The Question of " Absorbing Matter" in Space.--In the January number of the Astrophysical Journal (vol. xxxi., No. r, p. 8) Prof. Barnard discusses some of the "dark lanes," seen on a number of his beautiful photographs of nebulæ, from the point of view of their representing masses of actual absorbing matter. A nebulous region involving $\nu$ Scorpii is shown to be nearer than the general background of stars, and is at least partially transparent, but the absorption of the light of the stars behind it must be considerable, for it seems to show a distinct veiling tendency in certain regions. In the case of $\rho$ Ophiuchi nebula, also, there are dark lanes which tempt Prof. Barnard to believe in the existence of opaque matter in the sky, although, if there is, it must be there, as shown on the photographs, on a gigantic scale. If it does exist, it is probably in connection, in some way, with nebulæ, for it is in nebulous regions that it is found. A magnificent photograph of the $\rho$ Ophiuchi region is reproduced with the article, and Prof. Barnard believes that better photographs will show the nebulous region which he has photographed near $\pi$ and $\delta$ Scorpii to be connected with the $\nu$ Scorpii and $\rho$ Ophiuchi nebulosities.

Photographic Observations of $\eta_{\text {A Aulle. }}$-In No. 4385 of the Astronomische Nachrichten Herr A. Kohlschütter discusses a number of photographic observations of $\eta$ Aquilæ made at Göttingen during Ig06- 7 , and compares the results with those obtained from visual observations. This comparison shows that, essentially, the variability is the same photographically as visually, but the amplitude of the photographic variation is about 0.42 magnitude the greater.

Ephemeris for Daniel's Comet, igoge.-A revised ephemeris for Daniel's comet (1909e) is given in No. 4387 of the Astronomische Nachrichten. Dr. Ebell, having been informed by $\mathrm{Mr}$. Crommelin that the previous ephemeris, to which we directed attention last week, was incorrect, has calculated another, which he now publishes.

\section{PRESENTATION TO SIR EDWARD THORPE, F.R.S.}

$A \mathrm{~T}$ the Government Laboratory on Friday, February is, Sir Edward Thorpe was presented with a silver tea and coffee service and silver cigarette box subscribed for by former colleagues on the staff of the laboratory, and by members of other public departments intimately connected with the laboratory. Among the company present, besides Sir Edward and Lady Thorpe, were Sir George Murray, G.C.B., permanent secretary to the Treasury; Sir Thonas Elliott, K.C.B., secretary to the Board of Agriculture; Sir Nathaniel Highmore; Board of Customs and Excise; Mr. Middleton, Board of Agriculture; and Dr. J. J. Dobbie, principal of the Government Laboratory.

In making the presentation, Sir George Murray said he remembered being present at the opening of the Government Laboratory, and he had had ample opportunities of watching the progress of the department and the working out of what seemed in its inception to be a very novel and perhaps rather hazardous experiment. That experiment arose from a conviction that the demands of the Government on chemical science, as applied to the administrative business of government, could best be satisfied by a great central institution with an adequate equipment, and placed under the control of the most eminent man of science the Treasury could procure. The opposite idea was always dear to the hearts of departmental chiefs. They preferred a series of independent laboratories under their own control. From the moment of Sir Edward Thorpe's appointment, however, the laboratory gained the confidence of all the departments concerned, as well as of the public and the scientific world. He thought that the imposing variety of the work which was done in the laboratory could not fail to strike even the most uninstructed observer. The excellence of that work could be appreciated by only a very few.

Sir Thomas Elliott took this occasion of thanking Sir Edward Thorpe for the assistance, and more than the assirance, for the friendly advice and help that he had always shown himself ready to tender to the Board of NO. 2104 , VOL. 82$]$
Agriculture and Fisheries. Sir George Murray had referred to the relations between various departments, likening them to water-tight compartments. He, however, would compare them with so many foreign Powers treating with one another through the ordinary channels of diplomacy. He was sure that in overcoming such obstacles Sir Edward Thorpe showed the qualities of a statesman as well as those of a public official.

Mr. H. W. Davis, deputy principal, Mr. H. J. Helm, I.S.O., former deputy principal, and Mr. J. Connah, of the Customs branch of the laboratory, all referred to the excellent relations which had existed between Sir Edward and his colleagues, and to the great interest which Sir Edward had always taken in everything affecting the welfare of the laboratory staff.

Sir Edward Thorpe, in reply, said there was a larse number of those present who could have very little conception of the difference between the old state of affairs at Somerset House and the new state in the Government Laboratory. The stars were favourable when he planned the new building, and he was glad to acknowledge the great assistance he received from individual members of his own department. The laboratory was planned, as all laboratories should he, from the inside outwards. $\mathrm{He}$ at once recognised that the removal from Somerset House to the new building was the opportunity for making new departures quite impossible to achieve under the old conditions. With the improvements possible in the new building, economies had been effected which practically repaid the cost of the building several times over. Sir Edward said that, apart from the routine work, several very important matters had devolved upon the laboratory which had taxed its energies to the utmost. One of the earliest arose out of the imposition of the sugar duties. The laboratory was obliged to carry out experiments upon the thermal expansion and specific gravities of glucose solutions of varying qualities, and to weld the results into tabular form. The arsenic poison scare, too, resulted in the elaboration of an apparatus for the rapid and accurate determination of infinitesimal quantities of arsenic. This apparatus had since come into official use in several countries besides our own. Further, at the present time the laboratory was, in anicable conjunction with the Brewers' Institute, engaged in a series of experiments with a view to the reconstruction and amendment of the tables upon which the method for determining the original gravity of beer is based.

A vote of thanks to Sir George Murray was proposed by Dr. Dobbie, and carried with acclamation.

\section{BRILLIANT METEOR OF FEBRUARY I7}

N February 17 , at 6.8 p.m., a brilliant fireball was observed from various parts of the country. The evening twilight was strong, but the object created a very luminous effect; one observer, situated fully 250 miles from the meteor, estimated its light as quite three times as bright as Venus, and the streak or trail was visible for seven minutes.

Observations have come from the Thames near Sheerness, Guildford, Cardiff, and other places, and the radiant point appears to have been near Capella, from which a fine shower of February meteors is directed. The meteor was situated over Lundy Island or that region, and its height was probably from 88 to 46 miles, and velocity about I5 miles per second. As seen from Guildford, the streak remained on view nine minutes, when a cloud obscured it. It drifted far to the S.W. during its visibility, and it will be possible to compute the motion and direction of the drift very exactly.

More observations are required to define the real path with greater certainty, and amongst the large number of persons who saw the meteor it is hoped that some good records were obtained. The writer would be much interested in hearing some further particulars about the object, and especially with regard to its path in the heavens and place of the drifting streak. The meteor was probably the most brilliant observed in the British Isles hitherto this year.
W. F. DENNING. 